\title{
Design, Fabrication and Evaluation of a Hand-Operated Semi- Automatic Chopping Machine for Leafy Vegetables and Medicinal Herbs
}

\author{
P. D. Kahandage ${ }^{1 *}$, D.A.N. Darmasena ${ }^{2}$, E.J. Kosgollegedara ${ }^{1}$
}

\section{${ }^{1}$ Department of Agricultural Engineering and Soil Science, Faculty of Agriculture, Rajarata University of Sri Lanka, Anuradhapura, Sri Lanka. \\ ${ }^{2}$ Department of Agricultural Engineering, Faculty of Agriculture, University of Peradeniya, Sri Lanka.}

\section{Correspondence:} *pubudu2144@gmail.com, (iD)https://orcid.org/0000-0002-9825-4484

DOI: http://doi.org/10.4038/sljae.v2i2.44

\begin{abstract}
A hand-operated semi-automatic vegetable chopping machine was designed, fabricated and evaluated to introduce an efficient chopping machine to ease the preparation of leafy vegetables and herbal medicines. The main features and components of the chopping machine were integrated cutting and feeding mechanism, operating handle, cylindrical container, piston, collecting drawer and the frame. The machine was designed to operate manually reducing the operational \& capital cost and to ease the use in rural areas, where there is no electrical supply. A performance test was done for this machine using four different leafy vegetables and medicinal herbs [Mukunuwenna (Alternanthera sessilis), Kankun (Ipomoea aquatica), Gotu kola (Centella asiatica) and Kathuru murunga [Sesbania grandiflora)] in comparison with manual chopping using a general kitchen knife. Five unskilled males and females were involved in a performance test with three replicates. The three-factor factorial experimental design was used in the evaluation. The actual capacity and the efficiency of the chopping machine were $1.81 \mathrm{~kg} \mathrm{~h}^{-1}$ and $74 \%$, respectively compared to $1.02 \mathrm{~kg} \mathrm{~h}^{-1}$ and $76 \%$ of the manual kitchen knife. The average width of a particle cut by machine and kitchen knife were $1.87 \mathrm{~mm}$ and $3.38 \mathrm{~mm}$, respectively. According to the user-feedback, this machine is a safe, affordable and convenient device for processing vegetables and herbal medicines.
\end{abstract}

Keywords: Integrated cutting and feeding, Leafy vegetable chopping machine, Semiautomatic 


\section{Introduction}

Leafy Vegetables are categorized under protective foods, because they are highly beneficial for good health and disease prevention (Subhasree et al. 2009).

Globally, vegetables are processed in various ways in the day-to-day life (Darkwa and Darkwa 2013). Most of the time leafy vegetables are chopped into smaller pieces using a sharp knife as even and small vegetable particles increase food palatability. The sharpness of the knife and the experience of the person considerably affect the quality of chopped leafy vegetable particles. Chopping with a kitchen knife may cause injuries due to the sharpness. Therefore, the majority of employed young women in Sri Lanka seem to be reluctant to add leafy vegetables into their daily menu. This might be due to difficulty in chopping leafy vegetable into finer particles. Electrically driven large-scale slicing machines are available in the market and used in hotels and large-scale food processing plants. Those machines are not affordable and suitable for domestic use. In addition, most of the people may hesitate to purchase an electrically driven machine due to the higher cost of electricity and maintenance. Unavailability of spare parts and less reliability due to the low quality are some of other problems associated with most of the available electrically driven machines in the market. Therefore, a convenient and safer method of chopping leafy vegetables and herbal medicines need to be introduced.

The aim of this study was to introduce an efficient and convenient mechanical solution for leafy vegetable and medicinal herbs chopping. The results of this study will be useful for households, small scale food industries and herbal medicine producers.

\section{Methodology}

\section{Design concept}

This design integrated two main mechanisms as feeding and cutting, which were operated manually. A vertically rotating circular metal plate was fixed with two sharp blades and rigidly fastened to a horizontal threaded iron axis. A split nut was connected to the threaded iron so that the nut moves horizontally when the thread iron spins. This movement of split nut pushes the piston towards the cutter, together with leafy vegetables inside the container. The threaded axis was connected to an 
operating handle at the other end so that when the handle is rotated both the cutter and the feeding mechanism begin to function (Fig.1). Leafy vegetables should be packed tightly in the cylindrical container, in order to push them and cut simultaneously with handle movement. As the screw pitch of the threaded bar was $2 \mathrm{~mm}$ and two blades were fitted on exact opposite sides of the rotating plate, the theoretical minimum particle size would be $1 \mathrm{~mm}$. Drawer type collector was placed below the cutter to collect chopped leafy vegetables. The simple mechanism of this machine with a threaded bar and a split nut gives higher durability with low maintenance.

\section{Design considerations}

The machine was designed giving high concern for user-friendly operation in removal of the processed product. To minimize the operational cost and to facilitate easy operation in rural areas, where there is no electricity supply, the machine was designed to work on manual power. The locally available standard materials were used in the fabrication in order to ensure the easy production, repairing and maintenance at the village level. All parts of the machine getting in contact with food items were fabricated with food-grade materials to avoid any possible health issues.

\section{Main components of the machine}

Integrated cutting and feeding mechanisms, operating handle, cylindrical container, piston, collecting drawer and frame are the main components of leafy vegetable chopping machine (Fig. 1). Ideally, a product design needs to use a minimum number of parts requiring assembly. Fabrication requires fastening and assembly of several components and hence permanent, semi-permanent and removable fastening methods were used as reported by Timothy and Wentzell (2004). 


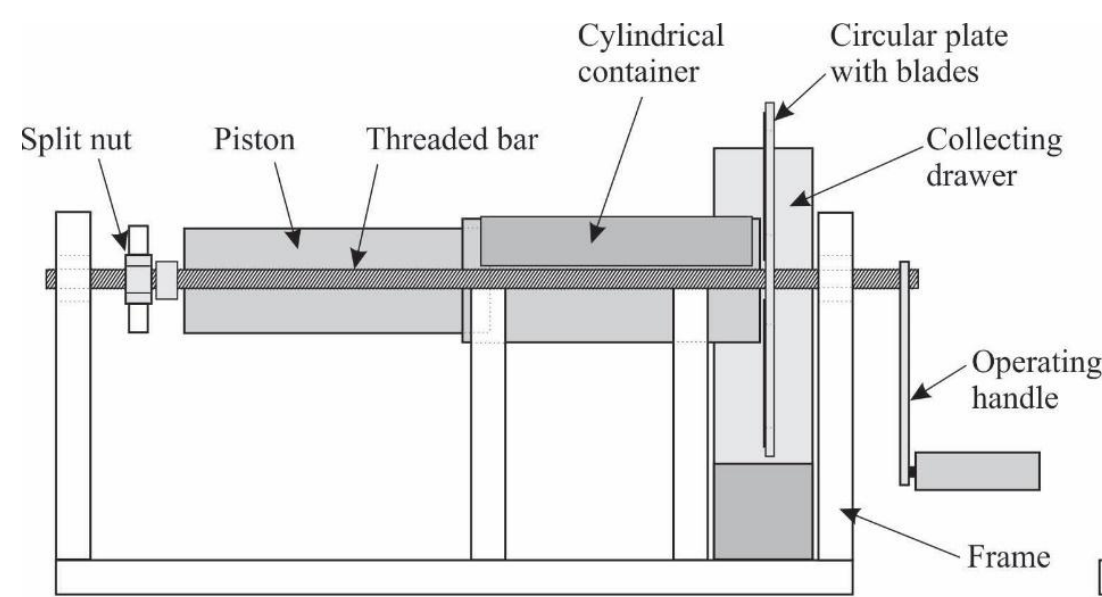

Front view

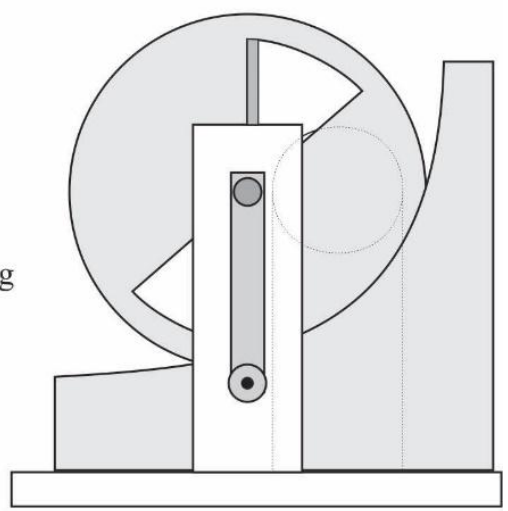

Side view

Figure 1: Front and side sketches of the machine

Forward and backward movement of the piston

The threaded bar is a screw which is a simple machine that works as a modified inclined plane. The screw pitch is the distance between the threads (David 2018). When the threaded bar of the integrated cutting and feeding mechanisms rotates the split nut moves linearly towards the cutting section together with the piston connected to it
(Fig. 2a). The same rotation action moves the sharp blades in the cutting section and leafy vegetables are subjected to cut while automatically getting pushed towards the cutting section. Two halves of the split nut get widen when arms are pressed against each other. Then the piston can be moved backwards easily and quickly without reversing the threaded bar (Fig. $2 b)$.



(a)



(b)

Figure 2: Spring loaded split nut (a) in its forward movement (b) backward movement 
Cylindrical container and the piston

The container was an open cylinder into which the piston moves from the rear end and pushes leafy vegetables in it towards the cutter fixed close to its front end. The capacity of the container was $500 \mathrm{~cm}^{3}$ with the dimensions of 6 $\mathrm{cm}$ and $18 \mathrm{~cm}$, respectively for diameter and length (Fig.3).

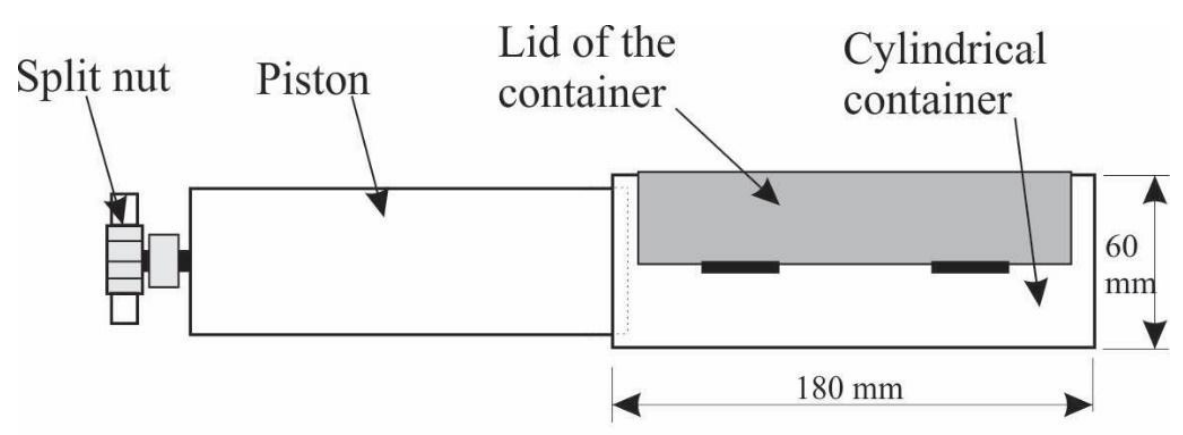

Figure 3: Container cylinder and piston

\section{Cutter section}

Two stainless steel sharp blades were fixed on the exact opposite sides of a stainless steel circular plate of which the diameter was $16 \mathrm{~cm}$ (Fig. 4).

\section{Collecting drawer}

The capacity of the drawer type collector placed under the cutter was
$600 \mathrm{~cm}^{3}$ that would not be too small to collect all cut

vegetables from the container. The special shape of the collector could collect all cut vegetable particles without dropping out. After cutting, the collector can be taken out very easily and emptied into another collector.

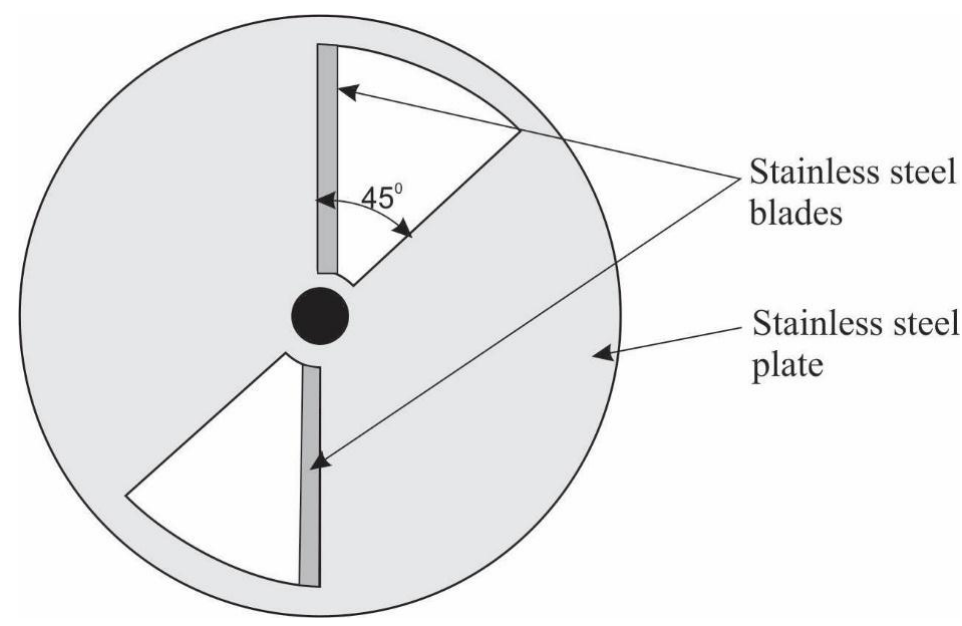

Figure 4: The cutter section 


\section{Material selection and fabrication}

Availability, suitability for the working conditions and servicing and the cost were the major factors considered when selecting materials (Khurmi and Gupta 2005). In addition, strength, durability, corrosion resistance and workability were the other factors considered. The frame was fabricated using hardwood. Container, piston and the cutter section were fabricated with stainless steel while the threaded bar and split nuts were mild steel. Fabrication was carried out in the Engineering Workshop, Faculty of Agriculture, Rajarata University of Sri Lanka.

\section{Evaluation of performance}

Performance of this machine was evaluated using commonly available four different leafy vegetables and medicinal herbs; Alternanthera sessilis (Mukunuwenna), Ipomoea aquatica (Kankun), Centella asiatica (Gotu kola) and Sesbania grandiflora (Kathuru murunga) compared to manual chopping with a general kitchen knife. The parameters considered were working capacity, quality of work, adaptability, operating speed and efficiency (RNAM 1983). Evaluation of the machine was done using five unskilled males and five unskilled females. The evaluation was repeated three times and considered as replicates. Following parameters were recorded for all the four leafy vegetables; time taken to cut a single batch (s), the weight of leafy vegetables cut within an hour (kg), the average width of a sliced particle (mmmeasured using a vernier calliper). In addition, injuries to operators and machine break downs were observed and recorded. Theoretical chopping capacity, Actual chopping capacity and Chopping efficiency were calculated with average recorded values using the equations, Eq. 01-03 The Three-factor factorial experimental design with the factors; gender with two levels (male and female), types of chopping with two levels (machine and manual) and types of leafy vegetables and medicinal herbs with four levels (Mukunuwenna , Kankun, Gotu kola and Kathuru murunga) was used for this study. Analyses of variance (ANOVA) were performed to test the significance of each factor and their interactions using SAS (9.1 Version). Mean separation was carried out using Tukey's mean separation procedure $(p<0.05)$.

Theoretical chopping capacity $\left(\mathrm{kg} \mathrm{h}^{-1}\right)=[W$ $(\mathrm{kg}) / \mathrm{t}(\mathrm{s})] \times 3600 \quad-E q .01$ 
Where, W - weight of the chopped leafy vegetables and medicinal herbs within ' $\mathrm{t}$ ' time

Actual chopping capacity $\left(\mathrm{kg} \mathrm{h}^{-1}\right)=$ Amount of leafy vegetables sliced within 1 hour Eq. 02

Chopping efficiency (\%) = (Actual slicing capacity/Theoretical slicing capacity) x 100 -Eq. 03

Pre-tested questionnaire was used to collect the feedback on easiness, appearance, user-friendliness and affordability of the machine from 25 users and data was summarized in tabular format.
After a series of tests and modifications, the design and the fabrication of the chopping machine was successfully completed (Plate 1). The cost of production of the machine was 6000.00 LKR, which includes both material and labour costs. However, the cost may be reduced further in bulk production.

\section{Evaluation of the machine}

Table 1 shows the important specification of newly fabricated handoperated semi-automatic vegetable chopping machine.

\section{Results and Discussion}

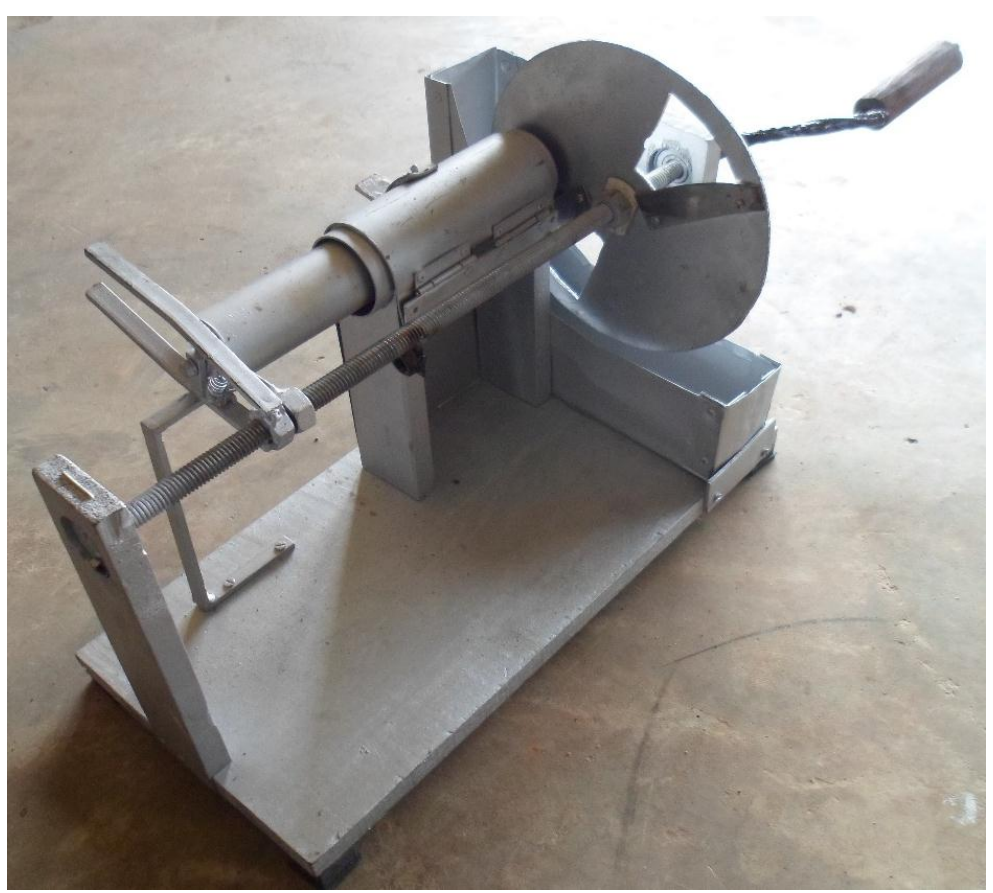

Plate 1: The fabricated hand-operated semi-automatic chopping machine 
Table 1: Specifications of the machine.

\begin{tabular}{ll}
\hline Parameter & Value \\
\hline Length of the machine & $47 \mathrm{~cm}$ \\
\hline Width of the machine & $25 \mathrm{~cm}$ \\
\hline Height of the machine & $25 \mathrm{~cm}$ \\
\hline The capacity of the container & $500 \mathrm{~cm}^{3}$ \\
\hline The capacity of the collector & $600 \mathrm{~cm}^{3}$ \\
\hline Screw pitch of the threaded bar & $2 \mathrm{~mm}$ \\
\hline
\end{tabular}

\section{The average width of sliced particles}

The average width of the cut vegetable pieces is given in Table. 2 .

As per the design specifications, the width of a cut particle needs to be $1 \mathrm{~mm}$. However, in the operational condition, it was approximately about $2 \mathrm{~mm}$ for all leafy vegetables tested. This is due to the different textures of leaves and stems,

which effect on the shearing action of the knife. The inconsistencies were due to dragging of leafy vegetables downward through the gap between the container and the cutter and may also be due to the sharpness of the blade.

With high proportion of stem pieces of Ipomoea aquatica the average size of cut pieces obtained were wider than $2 \mathrm{~mm}$.
The similar sizes of cut pieces were observed in the manual method (knife) too.

Table 2: Average width of the cut pieces of leafy vegetables

\begin{tabular}{|c|c|c|c|c|}
\hline & \multicolumn{4}{|c|}{$\begin{array}{c}\text { The average width of a cut } \\
\text { vegetable piece (mm) }\end{array}$} \\
\hline & \multicolumn{2}{|c|}{ Male } & \multicolumn{2}{|c|}{ Female } \\
\hline & Machine & Manual & Machine & Manual \\
\hline $\begin{array}{l}\text { Alternanthera } \\
\text { sessilis } \\
\text { (Mukunuwenna } \\
\text { ) }\end{array}$ & 1.70 & 3.75 & 1.85 & 2.85 \\
\hline $\begin{array}{l}\text { Ipomoea } \\
\text { aquatica } \\
\text { (Kankun) }\end{array}$ & 2.35 & 4.25 & 2.25 & 3.85 \\
\hline $\begin{array}{l}\text { Centella } \\
\text { asiatica } \\
\text { (Gotu kola) }\end{array}$ & 1.75 & 3.35 & 1.75 & 2.90 \\
\hline $\begin{array}{l}\text { Sesbania } \\
\text { grandiflora } \\
\text { Kathuru } \\
\text { murunga }\end{array}$ & 1.65 & 3.50 & 1.70 & 2.65 \\
\hline
\end{tabular}

Theoretical Chopping Capacity (TCC), Actual Chopping Capacity (ACC) and Chopping Efficiency (CE) of the slicing machine and manual slicing

TCC, ACC and CE of both chopping methods were calculated separately based on the gender of operators (Table 3), while Table 4 indicates their average values. 
Table 3: TCC, ACC and CE of manual chopping and mechanical chopping based on the gender of operators

\begin{tabular}{|c|c|c|c|c|}
\hline Type of leafy vegetable and medicinal herbs & Gender & Parameter & $\begin{array}{l}\text { Manual } \\
\text { chopping }\end{array}$ & $\begin{array}{l}\text { Mechanical } \\
\text { chopping }\end{array}$ \\
\hline \multirow[t]{6}{*}{ Alternanthera sessilis } & \multirow[t]{3}{*}{ Male } & TSC $\left(\mathrm{kg} \mathrm{h}^{-1}\right)$ & $1.03^{\mathrm{a}}$ & $2.34^{\mathrm{b}}$ \\
\hline & & ASC $\left(\mathrm{kg} \mathrm{h}^{-1}\right)$ & $0.75^{\mathrm{a}}$ & $1.82^{\mathrm{b}}$ \\
\hline & & CE (\%) & $72.82^{\mathrm{a}}$ & $77.78^{b}$ \\
\hline & \multirow[t]{3}{*}{ Female } & TSC $\left(\mathrm{kg} \mathrm{h}^{-1}\right)$ & $1.32^{\mathrm{c}}$ & $2.31^{\mathrm{d}}$ \\
\hline & & ASC $\left(\mathrm{kg} \mathrm{h}^{-1}\right)$ & $1.05^{c}$ & $1.76^{\mathrm{d}}$ \\
\hline & & CE (\%) & $79.55^{c}$ & $76.19^{\mathrm{d}}$ \\
\hline \multirow[t]{6}{*}{ Ipomoea aquatica } & \multirow[t]{3}{*}{ Male } & TSC $\left(\mathrm{kg} \mathrm{h}^{-1}\right)$ & $1.34^{\mathrm{e}}$ & $2.53^{f}$ \\
\hline & & ASC $\left(\mathrm{kg} \mathrm{h}^{-1}\right)$ & $1.05^{\mathrm{e}}$ & $1.96^{\mathrm{f}}$ \\
\hline & & CE (\%) & $78.36^{\mathrm{e}}$ & $77.47^{f}$ \\
\hline & \multirow[t]{3}{*}{ Female } & TSC $\left(\mathrm{kg} \mathrm{h}^{-1}\right)$ & $1.56 \mathrm{~g}$ & $2.51^{\mathrm{h}}$ \\
\hline & & ASC $\left(\mathrm{kg} \mathrm{h}^{-1}\right)$ & $1.36^{\mathrm{g}}$ & $1.92^{\mathrm{h}}$ \\
\hline & & CE (\%) & $87.18^{g}$ & $76.49^{\mathrm{h}}$ \\
\hline \multirow[t]{6}{*}{ Centella asiatica } & \multirow[t]{3}{*}{ Male } & TSC $\left(\mathrm{kg} \mathrm{h}^{-1}\right)$ & $1.43^{\mathrm{h}}$ & $2.51^{\mathrm{i}}$ \\
\hline & & ASC $\left(\mathrm{kg} \mathrm{h}^{-1}\right)$ & $1.03^{\mathrm{h}}$ & $1.9^{\mathrm{i}}$ \\
\hline & & CE $(\%)$ & $72.03^{\mathrm{h}}$ & $75.70^{\mathrm{i}}$ \\
\hline & \multirow[t]{3}{*}{ Female } & TSC $\left(\mathrm{kg} \mathrm{h}^{-1}\right)$ & $1.52^{\mathrm{j}}$ & $2.45^{\mathrm{k}}$ \\
\hline & & $\operatorname{ASC}\left(\mathrm{kg} \mathrm{h}^{-1}\right)$ & $1.23^{\mathrm{j}}$ & $1.84^{\mathrm{k}}$ \\
\hline & & CE (\%) & $80.92^{j}$ & $75.10^{\mathrm{k}}$ \\
\hline \multirow[t]{6}{*}{ Sesbania grandiflora } & \multirow[t]{3}{*}{ Male } & $\mathrm{TSC}\left(\mathrm{kg} \mathrm{h}^{-1}\right)$ & $1.12^{1}$ & $2.42^{\mathrm{m}}$ \\
\hline & & ASC $\left(\mathrm{kg} \mathrm{h}^{-1}\right)$ & $0.71^{1}$ & $1.65^{\mathrm{m}}$ \\
\hline & & CE (\%) & $63.39^{1}$ & $68.18^{\mathrm{m}}$ \\
\hline & \multirow[t]{3}{*}{ Female } & $\mathrm{TSC}\left(\mathrm{kg} \mathrm{h}^{-1}\right)$ & $1.33^{n}$ & $2.36^{\circ}$ \\
\hline & & ASC $\left(\mathrm{kg} \mathrm{h}^{-1}\right)$ & $0.97^{n}$ & $1.62^{\circ}$ \\
\hline & & CE $(\%)$ & $72.93^{n}$ & $68.64^{\circ}$ \\
\hline
\end{tabular}

Values with different letters show significant difference among treatments $(p<0.05)$.

Three way interactions between types of leafy vegetable, gender, and method of chopping was significant. Mechanical chopping showed a significant performance irrespective of the gender and type of leafy vegetable and medicinal herbs.

Females performed well in manual slicing than males and the performances of the female on different types of leafy vegetables were significantly different. Males showed significantly higher performances in mechanical slicing compared to the females, irrespective of the types of leafy vegetables and medicinal herbs.

Table 4: Average actual capacities and efficiencies of mechanical and manual chopping

\begin{tabular}{lll}
\hline & $\begin{array}{l}\text { Mechanical } \\
\text { chopping }\end{array}$ & $\begin{array}{l}\text { Manual } \\
\text { chopping }\end{array}$ \\
\hline $\begin{array}{l}\text { Average actual capacity of } \\
\text { male }\end{array}$ & $1.83^{\mathrm{a}} \mathrm{kg} \mathrm{h}^{-1}$ & $\begin{array}{l}0.88^{\mathrm{b}} \mathrm{kg} \mathrm{h}^{-} \\
1\end{array}$ \\
\hline $\begin{array}{l}\text { Average actual capacity of } \\
\text { female }\end{array}$ & $1.78^{\mathrm{a}} \mathrm{kg} \mathrm{h}^{-1}$ & $\begin{array}{l}1.15^{\mathrm{b}} \mathrm{kg} \mathrm{h}^{-} \\
1\end{array}$ \\
\hline $\begin{array}{l}\text { Average actual } \\
\text { chopping capacity }\end{array}$ & $\mathbf{1 . 8 1}^{\mathrm{a}} \mathrm{kg} \mathrm{h}^{-1}$ & $\mathbf{1 . 0 2}^{\mathrm{b}} \mathrm{kg} \mathrm{h}^{-}$ \\
\hline \begin{tabular}{l} 
Average efficiency of male \\
\hline $\begin{array}{l}\text { Average efficiency of } \\
\text { female }\end{array}$
\end{tabular} & $\mathbf{7 4 . 7 8}^{\mathrm{a}} \%$ & $71.65^{\mathrm{b}} \%$ \\
\hline $\begin{array}{l}\text { Average chopping } \\
\text { efficiency }\end{array}$ & $\mathbf{7 4 . 4 4}^{\mathrm{a}} \%$ & $\mathbf{8 0 . 1 4 ^ { \mathrm { b } } \%}$ \\
\hline
\end{tabular}

The objective of introducing this machine was to overcome difficulties in processing leafy vegetables and 
medicinal herbs; hence, unskilled labourers were selected for machine evaluation. According to the Table 3 , the actual capacities of the manual and mechanical methods significantly varied with the types of leafy vegetables/ medicinal herbs and the gender $(p<0.05)$. The reason could be the difference of force required to cut stems and leaves with the type of vegetables/ medicinal herbs and the difference of loading time due to the shape and size of leaves and stems. The Average Actual Capacity (AAC) of a male was $1.83 \mathrm{~kg} \mathrm{~h}^{-1}$ with an Average Efficiency (AE) of $74.78 \%$, while the AAC of a female was $1.78 \mathrm{~kg} \mathrm{~h}^{-1}$ with an AE of $74.11 \%$ (Table 4). However, no significant difference between male and female was observed with respect to $\mathrm{AAC}$ and $\mathrm{AE}$. As the machine was a manually operated, males were able to operate it easier than females, however the time losses for loading and unloading were similar with both gender. The AAC and $\mathrm{AE}$ of the chopping machine were $1.81 \mathrm{~kg} \mathrm{~h}^{-1}$ and $74 \%$ respectively, while the corresponding figures of the manual chopping were $1.02 \mathrm{~kg} \mathrm{~h}^{-1}$ and $76 \%$.

\section{User's feedbacks on the chopping machine}

Summary of the user feedback is given in Table 5.

Table 5: Summary of user feedback Parameters

\begin{tabular}{|c|c|c|c|c|c|}
\hline & $\begin{array}{l}\overrightarrow{0} \\
\dot{0} \\
0 \\
\overrightarrow{0} \\
\overrightarrow{0}\end{array}$ & ర్ & 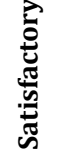 & $\tilde{\mathscr{D}}$ & $\begin{array}{l}\frac{\pi}{\pi} \\
\frac{\pi}{0} \\
\lambda_{0}^{\circ}\end{array}$ \\
\hline $\begin{array}{l}\text { Convenience of } \\
\text { operation }\end{array}$ & $64 \%$ & $24 \%$ & $12 \%$ & - & - \\
\hline Size of the machine & $84 \%$ & $16 \%$ & - & - & - \\
\hline $\begin{array}{l}\text { Overall performance } \\
\text { of the machine }\end{array}$ & $44 \%$ & $40 \%$ & $16 \%$ & - & - \\
\hline $\begin{array}{l}\text { Appearance of the } \\
\text { product }\end{array}$ & $92 \%$ & $8 \%$ & - & - & - \\
\hline $\begin{array}{l}\text { Overall product } \\
\text { quality }\end{array}$ & $72 \%$ & $20 \%$ & $8 \%$ & - & - \\
\hline Safety & $80 \%$ & $20 \%$ & - & - & - \\
\hline $\begin{array}{l}\text { Cleaning of the } \\
\text { machine }\end{array}$ & $60 \%$ & $32 \%$ & $8 \%$ & - & - \\
\hline $\begin{array}{l}\text { Affordability of the } \\
\text { machine }\end{array}$ & $76 \%$ & $20 \%$ & $4 \%$ & - & - \\
\hline
\end{tabular}

All parameters tested were above the satisfactory level. More than $90 \%$ of the users mentioned that the appearance of the machine is acceptable and more than $80 \%$ guaranteed the safety of the machine (Table 5). However, possibilities were identified for further improvements.

Conflicts of Interest: The authors declare that there are no conflicts of interest regarding the publication of this paper. 


\section{Conclusions}

The new machine showed satisfactory results with a capacity of $1.81 \mathrm{~kg} \mathrm{~h}^{-1}$ with $74.44 \%$ efficiency. The capacity and efficiency of the machine were affected by the type of leafy vegetables/medicinal herbs and the gender. The machine was observed to be yielding thinner cut pieces compared to the manual chopping (i.e. with a knife). Hence, this machine can be efficiently used in the preparation of some herbal medicines, which requires very fine chops. The total cost of the machine at the research level was 6000.00 LKR. The overall performance, appearance, safety and cleaning were at an acceptable level.

\section{References}

Darkwa S, Darkwa A A (2013). The Use of Indigenous Green Leafy Vegetables in the Preparation of Ghanaian Dishes. J Food Process Technol 4(12): 286.

David C (2018) How to calculate Mechanical Advantage Screw, [online] Available at: https://sciencing.com/calculatemechanical-advantage-screws5824401.html. Accessed on 14 April 2020.
Khurmi R S, Gupta J K, (2005). A Text Book of Machine Design. New Delhi: Eurasia Publishing House (PVT.) LTD.

RNAM (Eds). (1983) Economic and Social Commission for Asia and Pacific Regional Network for Agricultural Machinery: RNAM Test Codes and Procedures for Farm Machinery. Thailand, United Nations Industrial Development Organization.

Subhasree B, Basker R, Keerthana R L, Susan R L, Rajasekaran P (2009) Evaluation of Antioxidant potential in selected green leafy vegetables. J Food chemistry 115(4): 1213-1220.

Timothy H, Wentzell P E (2004) Machine Design. [online] Available at: http://www.uni.edu/ rao/MD06\%20Fasteners.pdf. accessed on 12 July 2014. 